
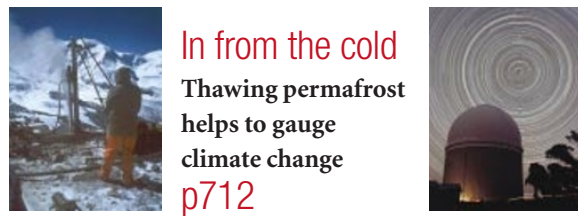

Ground control

Thawing permafrost helps to gauge climate change p712 Optical astronomy poses Australian challenge p714

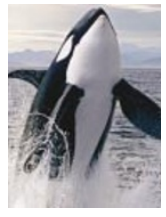

Killer cure

Biologists seek to get mammal numbers back on track p715

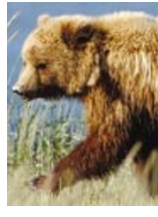

\title{
Chinese fusion method promises fresh route to human stem cells
}

\section{Carina Dennis}

Biologists in China have reprogrammed human cells by fusing them with rabbit eggs emptied of their genetic material. And they have extracted stem cells, which have the potential to form a wide array of different cell types, from the resulting embryos.

The researchers, led by Huizhen Sheng of Shanghai Second Medical University, think that these 'derived' stem cells could provide scientists in the field with an alternative to stem-cell lines extracted from human embryos. But some researchers who have seen the work point out that the derived cells don't seem to have the same ability as human embryonic stem cells to grow indefinitely in culture.

The work will be published online this week in Cell Research, a peer-reviewed journal supported by the Chinese Academy of Sciences. The paper will appear in print later this month (Y. Chen et al. Cell Res. 13, 251-263;2003).

Sheng's work has already created a buzz after rumours of it circulated in the scientific community and were reported in The Wall Street Journal in March 2002 (see Nature 419, 334-336; 2002). The publication is likely to reignite debate over the ethics of crossspecies reprogramming. But cell biologists say that having the data available for public discussion will help researchers and regulators to decide what kinds of cross-species work should be pursued.

Reprogramming adult cells to assume an embryonic state could offer a way to grow new cells and tissues to replace those lost to ageing and disease. And using an individual's own cells, in a process often called therapeutic cloning, may avoid problems of the immune system rejecting the cell therapy.

To reprogramme an adult cell, it can either be fused with or have its nucleus injected into an egg that has had its own nucleus removed. The reconstituted cell is then tricked into dividing as if it were an embryo, with all memory of its previous life as a liver, skin or kidney cell erased. After 5-7 days, embryonic stem cells - which can seemingly grow indefinitely — can be extracted from the growing ball of cells. By

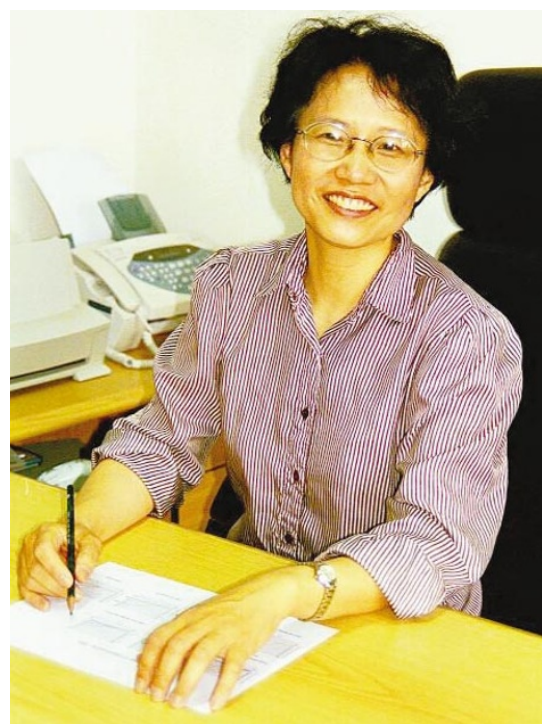

changing the growth conditions, these cells can then be coaxed to develop into many different cell types.

Until now, scientists have only been able to generate animal stem-cell lines from the reprogrammed nuclei of cells. "This is the first paper to convincingly show that you can get human reprogramming," says Robin Lovell-Badge, a cell biologist at the National Institute for Medical Research in London.

Sheng claims to have successfully reprogrammed cells from the foreskin tissues of males aged 5, 42 and 52 years and from the facial skin of a 60-year old woman. "It just goes to show that age doesn't matter," says Lovell-Badge.

But Sheng has had a tough time convincing some experts. "I first submitted the paper more than two years ago," she says. It is understood that the paper was considered and rejected by other journals before this week's publication in China.

"I was frustrated that it took so long to get the paper published," Sheng says, "and it still may take a while for people to accept the work. But the scientific community has the right to question the details of the work and we have a responsibility to respond to them."

Doug Melton a cell biologist at Harvard University, for one, has concerns about the

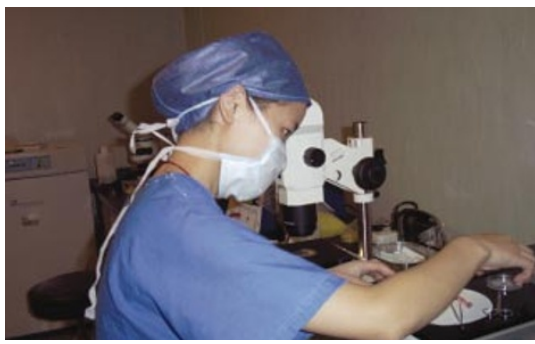

A team led by Huizhen Sheng (left) has devised a technique for reprogramming adult human cells by fusing them with empty rabbit eggs (above).

nature of the derived embryonic stem-cell lines. "I'm convinced that the cells do have the capacity to differentiate into different cell types, but it's unclear how long the cells can grow in culture," he says.

"It would be very surprising if the cell lines were stable," Melton adds, noting that many interspecies hybrids are unstable, because of incompatibilities between the nucleus and mitochondria (the energyproducing compartments of cells) from different species.

And Rudolf Jaenisch, of the Whitehead Institute in Cambridge, Massachusetts, is not convinced that the derived cells meet the usual criteria for embryonic stem cells. "An important criterion is indefinite growth," he says. "This is not shown."

But reservations aside, Melton is pleased that the work has finally seen the light of day. "I'm glad to see it published as it will encourage others to try it," he says.

At this stage, Sheng has no plans to use stem cells created by her method to treat humans. "It is a research tool. But there is the possibility that if it were proved to be safe enough for clinical use, it could provide a solution to human egg shortages for reprogramming in the future," says Sheng.

While the scientific community debates her work, Sheng is keen to test the embryonic stem cells she has generated in an animal model. "It will be important to see whether they will be tolerated by the immune system and whether they can correct an animal model of human disease," she says.

www.cell-research.com 